\title{
Recruitment and retention strategies and methods in the HEALTHY study
}

\author{
KL Drews ${ }^{1}$, JS Harrell ${ }^{2}$, D Thompson ${ }^{3}$, SL Mazzuto ${ }^{1}$, EG Ford ${ }^{4}$, M Carter $^{5}$, DA Ford ${ }^{6}$, Z Yin $^{7}$, \\ AN Jessup ${ }^{2}$, J-B Roullet ${ }^{8}$, and for the HEALTHY Study Group \\ ${ }^{1}$ Biostatistics Center, George Washington University, Rockville, MD, USA \\ ${ }^{2}$ School of Nursing, University of North Carolina at Chapel Hill, Chapel Hill, NC, USA \\ USDA/ARS Children's Nutrition Research Center, Baylor College of Medicine, Houston, TX, \\ USA \\ ${ }^{4}$ Center for Obesity Research \& Education, Temple University, Philadelphia, PA, USA \\ ${ }^{5}$ Western Psychiatric Institute and Clinic, University of Pittsburgh Medical Center, Pittsburgh, PA, \\ USA \\ ${ }^{6}$ Department of Pediatrics, University of California, Irvine, CA, USA \\ ${ }^{7}$ Department of Health and Kinesiology, University of Texas at San Antonio, San Antonio, TX, \\ USA \\ ${ }^{8}$ Division of Metabolism, CDRC-P, Oregon Health \& Science University, Portland, OR, USA
}

\section{Abstract}

HEALTHY was a 3-year middle school-based primary prevention trial to reduce modifiable risk factors for type 2 diabetes in youth. The study was conducted at seven centers across the country. This paper describes the recruitment and retention activities employed in the study. Schools and students were the focus of recruitment and retention. Each center was responsible for the recruitment of six schools; eligibility was based on ability to enroll a sufficient number of predominately minority and lower socioeconomic status students. Study staff met with district superintendents and school principals to verify the eligibility of schools, and to ascertain how appropriate the school would be for conducting the trial. Sixth grade students were recruited employing a variety of techniques; students and their parents did not know whether their school was randomized to the intervention or control arm. This cohort was followed through sixth, seventh and eighth grades. In the eighth grade, an additional sample of students who were not originally enrolled in the study was recruited in a similar manner to participate in data collection to allow for cross-sectional and dose-response secondary analyses. Parents signed informed consent forms and children signed informed assent forms, as per the needs of the local Institutional Review Board. Parents received a letter describing the results of the health screening for their children after data collection in sixth and eighth grades. Retention of schools and students was critical for the success of the study and was encouraged through the use of financial incentives and other strategies. To a large extent, student withdrawal due to out-migration (transfer and geographical relocation) was beyond the ability of the study to control. A multi-level approach

(C) 2009 Macmillan Publishers Limited All rights reserved

Correspondence: Dr KL Drews, Biostatistics Center, George Washington University, 6110 Executive Boulevard, Suite 750, Rockville, MD 20852, USA. kdrews@bsc.gwu.edu.

Conflict of interest

The authors declare no conflict of interest. 
that proactively addressed school and parent concerns was crucial for the success of recruitment and retention in the HEALTHY study.

\section{Keywords}

recruitment; retention; type 2 diabetes; middle school; adolescents; prevention

\section{Introduction}

HEALTHY was a middle school-based primary prevention trial conducted over three academic years between 2006 and 2009 in 42 schools, six at each of seven centers across the country. Half of the schools were randomly assigned to receive an intervention designed to reduce risk factors for type 2 diabetes by implementing school-wide changes in nutrition, physical activity and health education and promotion.1 All study schools had student populations that were predominately minority and/or of lower socioeconomic status. We recognized that the students and their parents/guardians may have been unfamiliar with or suspicious of research studies. 2 Therefore, it was particularly important to inform the students and their parents/guardians about research philosophy and methods, about the study and its relationship to them, and about the benefits and risks of participation. Students were enrolled to participate in data collection procedures; the intervention was delivered on a school-wide or grade-wide level, and therefore students were not able to refuse to be exposed to the intervention. Recruitment materials and efforts highlighted the main benefit of participation, which was a comprehensive health screening to assess risk of type 2 diabetes and other medical problems. It was clear to the study group from the beginning that a well-organized campaign was crucial for the success of recruitment and retention. A Recruitment and Retention Committee was appointed to develop strategies and materials. Here we present and discuss the procedures used to recruit and retain schools and students in the HEALTHY study.

\section{Background and rationale}

Well-designed recruitment and retention efforts are vital to the success of all research trials. Several groups have reported their experiences gaining access to schools for research, as well as recruiting students into school-based primary prevention trials.3-6 School recruitment strategies emphasize (1) the importance of recruiting on multiple levels, including the community, school boards, superintendents of schools, principals and teachers, 3 (2) getting endorsement of the study from the principal and teachers, 3,4,7,8 (3) the need to be familiar with the organization of the school5 and (4) the benefit of multiple reminders to increase participation.6 Student demographic composition, school size, administrative policies and community factors can influence recruitment of schools and students.

Investigators have also described recruitment procedures used in their school-based studies of children and adolescents.7-14 Common to the success of recruitment in these studies was the use of a variety of approaches to recruitment,7,11,15 designed to individualize recruitment efforts according to site or school district $9,10,16$ by taking into account the cultural, educational, economical, social, psychological and organizational characteristics of the schools.4,9 On the student level, several researchers have reported that it was harder to recruit older students (especially those aged 13-15) than younger students.7,17 Monetary or other tangible support at both the school and student level was important.4,10,11 However, Pound 18 reported that the perception of the value of the study to students and the community was one of the most important reasons for school participation. 
Less information is available on retention procedures. Good19 summarizes activities to enhance retention in a clinical trial, emphasizing that retention activities in control and intervention groups should be identical. In a focus group of African-American adolescents aged 13-17, successful retention depended on the actual content of the intervention, the characteristics of the teachers and researchers involved, relationships with researchers and other teens, and incentives such as food, fun and money. 20

\section{Lessons learned from pilot studies}

Before the main study, three centers conducted a health screening with eighth grade students in four schools at each center.21 The screening consisted of various health and anthropometric measurements, including a fasting blood draw and administration of a full oral glucose tolerance test (OGTT) in the school setting. Eligible schools had at least 50\% ethnic minority representation (African American, Hispanic and/or American Indian), with at least $50 \%$ of students qualifying for free or reduced-price meals.

Two of the three centers conducted post-pilot study parent interviews to learn more about the reasons parents did and did not allow their children to participate in the health screening, and some of the considerations that went into that decision. After the screening at each center, semi-structured telephone interviews were conducted by trained project staff following a standard procedure and script. A total of 59 out of 60 recorded parent interviews provided analyzable transcripts. Forty interviews were with parents of participating students and 19 interviews were with parents of nonparticipating students. The parents were mostly Hispanic (76\%) or African American (22\%), largely female (92\%), generally with an annual household income less than $\$ 30000$ (84\%), and no more than a high school education $(81 \%)$.

Parents were asked how they found out about the health screening. The most frequently recalled recruitment strategy was the study information sheet (92\%), a colorful flyer that provided information about the screening and how to enroll; $47 \%$ also mentioned receiving phone calls about the study. About three-quarters gave as a reason their child's interest in participating in the study (76\%).

Among important reasons parents wanted their child to participate in the health screening included having a family history of diabetes $(88 \%)$, wanting to learn about their child's health status (56\%), and the convenience of having the screening at school (53\%). Many parents were not sure if their child was susceptible to developing diabetes in the next few years $(41 \%)$ or as an adult $(46 \%)$. When asked why they thought their child wanted to participate in the screening, the most often cited reason was the incentive of a gift card or money (37\%). When parents were asked about concerns they may have had about their child participating in the screening, the blood draw was the most frequently reported concern (49\%) (for example, amount of blood drawn and sanitary conditions). Other concerns were the potential consequences of the results of the screening for their child $(44 \%)$ and sending their child to school fasting since midnight (32\%).

Parents of nonparticipating students reported that the primary reasons as to why they did not give permission for their child to participate were the following: not understanding the informed consent form (37\%), excessive paperwork (32\%) and the child's refusal to participate (32\%). Another $32 \%$ reported running out of time to complete the enrollment paperwork, forgetting to sign the consent forms or giving the forms to their child to turn in and the child forgetting. Parents also reported confusion related to receiving multiple copies of the consent materials (one copy was provided to send back and one to keep), language or communication difficulties (all materials were provided in English and Spanish) and poor comprehension. Parents were asked to provide suggestions on how to encourage other 
parents to allow their child to participate in a screening of this type. The most common suggestions were offering encouragement (53\%), involving parents who had past experience with participation (24\%) and providing educational information (19\%).

One center conducted a focus group with 44 eighth grade students before the health screening to determine what would interest them in participating in the study. Most (52\%) were African American, with 37\% White and 11\% American Indian. Students were concerned about the blood draw. They were enthusiastic about the study, indicating that participating in the study gave them a sense of 'helping with a good cause', that is, understanding diabetes. The students were also very excited about the monetary incentive of $\$ 50$ for taking part in the health screening.

Although only a fasting blood draw and not a full oral glucose tolerance test was carried out in the HEALTHY trial, findings from the student focus groups and parent interviews suggested that clearly addressing parent and child concerns about the procedures related to the health screening (especially drawing blood) and educating parents about risks for type 2 diabetes in children, would likely facilitate recruitment efforts for a school-based screening. Both parents and students had indicated that the term 'diabetes screening' made them fearful about having the disease; they also expressed concern about the need to come to school fasting. In response to these concerns, the student data collection in the HEALTHY study was termed a 'health screening' and a free breakfast was provided after the screening.

\section{Development of materials for recruitment and retention}

Based on lessons learnt in pilot studies, the Recruitment and Retention Committee determined that the information distributed to parents and students needed to use simple language, use no jargon or colloquialisms, provide information about susceptibility and risk factors for diabetes and clearly explain all procedures, such as the fasting blood draw. Each child's health screening results and their interpretation were sent in a letter to parents/ guardians after each data collection period. If a health problem was identified, parents were told to contact their health care provider and, as needed, were assisted in their efforts to locate health care.

In all, two basic sets of materials were developed. One set of standard materials was centrally produced including brochures, posters, annual holiday cards, videos and incentive items, such as branded backpack, CD case, pens and pencils. The other set of materials was templates that could be locally modified. With the exception of the holiday card greeting, all standard print materials designed for use by either students or parents were available in both English and Spanish. Translation of modified template materials was left to the individual centers. Student materials were written at or below a sixth grade reading level, and materials for the parents were written at or below a ninth grade reading level.

Standard materials and templates were reviewed and approved by the entire study group before each center submitted them to the local Institutional Review Board for approval. The rigorous review and approval process was designed to ensure the materials and procedures developed were ethical, non-coercive and uniformly acceptable across the 42 study schools. Table 1 lists recruitment materials and Table 2 lists retention materials.

\section{Recruitment methods and procedures}

\section{Recruitment at the school level}

The school eligibility criteria included having a student body that was representative of the pediatric population at risk for type 2 diabetes, annual student attrition from all causes 
historically not greater than $25 \%$, projected number of participating students followed for the entire study from sixth through eighth grades at least 50, adequate physical education facilities, agreement to be randomized to either intervention or control and broad agreement at all levels to comply with study procedures. In addition, the school or district had to obtain a Federal Wide Assurance to conduct federally funded research. A complete listing of school eligibility criteria is reported elsewhere. 1

After a list of potential schools was identified by each center, the principal investigator and the project coordinator contacted the superintendent of schools and other key individuals at the district level and provided them with an overview of the study. Meetings were then scheduled with school principals during which they were given an informational notebook (see Table 1). To ensure full school support, project staff met with school personnel who would play key roles if the school was randomized to administer the intervention, including the food service manager and physical education department head. Project staff made every attempt to ensure that the principal agreed to all aspects of the study and was willing to have his or her school assigned to either the control or the intervention arm of the study. In addition, the staff asked for feedback from the principal about possible barriers that might be encountered in the school and discussed ways to overcome them. Clear lines of communication with appropriate school administrators and staff were assured. The study provided financial incentives to each school to promote both recruitment and retention. Control schools got higher amounts to compensate for the equipment and resources that were associated with the intervention (see Table 2).

It was not feasible to impose the signing of an 'informed consent form' at the school or district level. At the discretion of the center, either a letter of agreement or memo of understanding could be obtained from each school. The document outlined the school administrator's understanding of his or her school's commitment to adhere to the study protocol regardless of changes in personnel or environment, agreement to randomization, including the implementation of the intervention if assigned, and accommodation of data collection.

After a school was selected to participate in the study, materials were provided to school faculty and staff to explain the study and their role in its success. School randomization to either intervention or control occurred before student recruitment. Study staff and key school administrative personnel were informed of the randomization assignment early to facilitate planning in food services and class scheduling in the 21 schools assigned to intervention.

\section{Recruitment of sixth grade students}

Unlike a typical clinical trial with extended periods of recruitment and enrollment, for the HEALTHY primary prevention trial, sixth grade students were recruited and enrolled during a single campaign focusing on participation in health screenings and data collection procedures. Students and parents were blinded to their school's randomization assignment during recruitment and health screening, and the intervention was not implemented until the second semester of sixth grade after the completion of baseline data collection. Recruitment presentations and materials clearly indicated that data to be collected included measurements of height and weight, waist circumference, blood pressure and a fasting blood draw to determine insulin, glucose and lipids. The information also made it clear that the complete health screening data collection would occur at the beginning of sixth grade (fall 2006) and end of eighth grade (spring 2009), and that height and weight alone would also be collected at the end of seventh grade (spring 2008).

Although official recruitment did not begin until the start of the sixth grade school year 2006 , the centers had the option to conduct 'pre-recruitment' activities by going to feeder 
schools in spring 2006, to middle school orientation meetings, or to other school or community meetings suggested by the school or district administration or a local advisory board. These outreach efforts served to familiarize the students and their parents/guardians with the study and reduce anxiety associated with participating. All pre-recruitment sessions were informational in nature and no actual enrollment was conducted. Materials that supported this effort included videos and/or PowerPoint presentations that provided a general description of type 2 diabetes and its risk factors, the study goal of reducing risk factors for type 2 diabetes in adolescents and a description of the health screening procedures.

Actual student recruitment began in each school after the official school opening in the fall of 2006 (sixth grade). Activities, events and materials associated with the recruitment efforts were designed to gain the attention and acceptance of students, to gain parental support for the study and to encourage participation. A menu of study-sanctioned recruitment activities was developed and each center was allowed to customize its recruitment activities to meet local needs. The menu of activities included the following: (1) making presentations or announcements to students in classes, in the cafeteria and during assemblies; (2) attending student groups or clubs, parent-teacher organizations, principal meetings and meetings of other relevant groups; (3) providing study information and/or making presentations to parents and students during back-to-school nights, registration nights, open houses, parent information sessions and health fairs; (4) using school-based advertising and dissemination opportunities such as school newsletters and school-wide email systems; (5) distributing incentive items, such as t-shirts, lanyards and pens branded with the study logo, to school faculty and staff to show broad-based school buy-in; and (6) handing out raffle tickets for donated items to students who came to back-to-school activities.

A recruitment packet was provided to every student in the sixth grade during the fall of 2006. The packet contained letters from the study center principal investigator and the school principal to the parents/guardians of the student, a brochure that described the study, its objectives and basic information about data collection, parent informed consent forms, student informed assent forms and a pen to facilitate the completion of materials. The packet also contained a form for the collection of basic health and socioeconomic information about the family. The contents of the recruitment packet are further described in Table 1.

Additional recruitment materials were developed based on feedback from pilot studies. Large eye-catching posters and flyers announced recruitment, reminded students about the need to return consent forms, and provided health screening time and location information. A student recruitment video was produced to alleviate fears about the blood draw and addressed why the study was important and how to sign up. A parent recruitment video provided information about the study and encouraged parents to allow their child to participate in the study. All materials designed to assist with student recruitment are given in Table 1.

Recruitment culminated with the return of the consent/assent forms for participation in the study. Students who returned a consent/assent form, signed or unsigned, received a small promotional giveaway item. Those who provided signed consent were scheduled to participate in the health screening. All students who completed the health screening in the sixth grade received a $\$ 50$ gift card and a small promotional giveaway item. Students who had completed health screening could show their classmates what they received and describe their experience, and thus may have had a positive influence on those students who were still considering whether to participate or not. The recruitment period extended through the end of the health screening in each school. 
Follow-up recruitment was permitted, but had to be conducted equivalently in both intervention and control schools. Extra efforts were made for schools whose enrollment rate was significantly lower than the rates in other schools or lower than what was needed to guarantee adequate sample size.

\section{Recruitment of eighth grade students}

Eighth grade students who had not enrolled to participate in the study in sixth grade were given an opportunity to enroll for the end-of-study health screening. These student data were combined with the rest of the end-of-study data from the initial cohort and used to conduct a cross-sectional dose-response type secondary analysis, where length of time in an intervention school represented the exposure 'dose'.1 The strategies and approaches used to recruit the eighth graders were similar to those used to recruit students in the sixth grade. Recruitment of eighth graders could begin as early as the start of the eighth grade school year, but no later than 2 weeks before health screening began at each school. To ensure equivalent recruitment efforts in both intervention and control schools, study staff involved with intervention activities were not allowed to participate in recruitment activities. (These staff members had been allowed to participate in sixth grade recruitment, since it occurred before the launch of the intervention.)

\section{Retention methods}

For the integrity of the study and the interpretation of results, it was important that dropout and withdrawal be minimized. As recruitment took place at both school and student levels, retention efforts also occurred on both levels. The methods employed in retention activities are summarized in Table 2.

\section{Retention at the school level}

Retention strategies were designed to maintain contact, awareness and 'buy-in' equivalently across all 42 schools. Awareness and interest remained high in the 21 intervention schools because of the greater frequency of contact, and the constant presence of intervention events and activities. To balance that continuous presence of HEALTHY in the intervention schools, the principal investigator and/or project coordinator maintained personal contact with the principal and other officials in the control schools to reinforce the importance of their continued participation in the study, to thank them for their continued participation and to ask for suggestions to improve the next round of data collection.

A menu of study-sanctioned retention activities was provided for each center to use in both control and intervention schools. The activities included providing annual monetary incentives to the schools (mandatory) and maintaining good communications with school personnel. The annual compensation schools received for participating in the study were used at the discretion of the school administration for program enhancement. The control school amounts increased annually more than the intervention schools to motivate continuation in the study, as well as to somewhat off-set what the intervention schools were receiving in terms of equipment and food service cost recovery. Rapport between school and study staff depended on good communications skills. Study staff received training on local culture and customs. The study provided schedules of data collection activities to school administration and faculty showing how study procedures fit into the school calendar, accounting for testing, holidays and other events. Each center sent annual holiday/new year cards to superintendents, principals, faculty and staff. Centers also provided school-specific summary reports of the aggregate results of the student data collection to school administration and superintendents. In addition, centers gave school staff and teachers 
periodic personalized incentives and thank-you gifts, such as handwritten thank you notes, gifts and snacks at teacher meetings.

To facilitate involvement in the study by school personnel, study staff met with school officials and teachers regularly during each semester of the study to go over all activities and obtain their input. Teachers were provided with specifics about each data collection session and were reminded of dates, times and places for health screening by posters displayed throughout the school and announcements in school newsletters or bulletins, or through school-wide communications. A list of materials associated with school retention is provided in Table 2 .

\section{Retention at the student level}

In the HEALTHY primary prevention trial, both in and out migration were expected among the student populations. For the most part, out-migration was due to transfer and relocation that had nothing to do with the study intervention or procedures and that would be equivalent across intervention and control schools. Therefore, student retention efforts in HEALTHY focused on retaining those students who were enrolled in the trial and remained in the school. To this end, study staff attended functions for parents, such as parent-teacher organization meetings or back to school nights, to explain the role of the study in the school. Involvement of the study staff at these meetings ranged from giving brief presentations with time for questions and answers to setting up a table and distributing general information about diabetes and the study. Study staff involved with the delivery of the intervention were not allowed to participate in the retention activities. Each field center used similar retention activities in all schools. Periods of heightened retention activities at each school were associated with student data collection at the end of seventh and eighth grades. Materials used for student retention are listed in Table 2.

By the time of seventh grade data collection in spring 2008, over a year had elapsed since initial enrollment and sixth grade baseline data collection. A reminder letter from the principal investigator (PI) of each center was distributed to parents/guardians to reinforce the importance of the study, and provide information about the upcoming brief data collection of weight and height. Letters were also distributed to students in the cohort to make them aware of what to expect during data collection. Posters were displayed in each school with information regarding the date, time and place for data collection activities. Once data collection was complete, the students received another small incentive item along with $\$ 10$ in cash or gift card. Similar to sixth grade, parents/guardians of all students who participated in data collection activities received a feedback letter with the child's height, weight and body mass index along with a brief explanation of the results.

As the eighth grade end of study data collection in spring 2009 again included a full health screening with fasting blood collection, information was distributed similar to that at baseline. An informational brochure explaining the end of study data collection was distributed to parents/guardians no later than 2 weeks before health screening began. Centers had the option to send a short letter to parents/guardians reminding them that they had already consented to let their child participate in data collection, the timeframe for data collection, the type of data to be collected and contact information for study staff in case any questions arose. Students also received a reminder card about their agreement to participate in the end of study health screening and any additional information about data collection. Large posters with the HEALTHY logo were displayed in the school to not only encourage recruitment, but also to provide information about health screening. On the night before a student's scheduled health screening, study staff called the parent/guardian with a reminder to send the child to school fasting the next morning. Once the health screening was complete, the students received a $\$ 60$ gift card and a small incentive item. Finally, the 
parent/guardian received a feedback letter presenting the results of the child's health screening for both the sixth and eighth grades.

\section{Summary and discussion}

Successful recruitment at the school level began by developing and presenting a clear message to all involved about the value that their participation in the study brought to the students at their school and the community at large. Gaining buy-in for the study was necessary at all levels. First, it was necessary to get the superintendents on board. Their support was essential in enlisting the school principals. Finally, the administration's support of the project was a major motivating factor for the school faculty and staff. Without a firm commitment from superintendents, principals, faculty and staff, the recruitment of schools and students into the study would not have been successful. Creating a partnership with the faculty and staff at each school provided study staff with a heightened awareness of school culture and knowledge of possible pitfalls. Although a letter of agreement or memo of understanding between the school and the study center did represent a mutual bond or agreement, like a patient informed consent form, it could be revoked. During HEALTHY, administrative personnel changes occurred at the school and district levels. Fortunately, no school refused to participate further and withdrew from the study. To what degree this was due to the diligent retention efforts of the study staff cannot be known.

Student recruitment strategies were bolstered by knowledge and experience gained during pilot work. Potential problem areas were identified and addressed during recruitment planning. Motivating factors for enrollment were also identified; for parents it was the health screening feedback letters and for students it was the monetary compensation. A menu of recruitment options allowed for customization at each center to accommodate the variety of audiences. Finally, the continuation of recruitment activities after the start of health screening in each school allowed for peer influence to be a factor in overall student recruitment.

Retention activities occurred on multiple levels and they were guided by a few simple principles. First, multiple and continual reminders of participation as well as a continued presence in the school were paramount. It was also essential that all activities designed to enhance retention were identical at the schools, regardless of randomization assignment. Constantly fostering good-will and buy-in was key to continued participation and was accomplished through multiple avenues, but most importantly by fulfilling promises made to schools, parents and students. Finally, continued monetary compensation to schools as well as to students was an essential element for successful retention. In conclusion, the HEALTHY study adopted a rigorous but flexible approach that focused on recruitment and retention of all levels of participants in a multi-center, school-based primary prevention trial.

\section{Acknowledgments}

We thank the past and present investigators on the Recruitment \& Retention Committee who were Joanne Harrell (chair), Lisa Bouchard, Barbara Curlee, Mackenzie Dobbins, Kimberly Drews, Debby Ford, Linn Goldberg, Katie Hindes, Ann Jessup, Francine Kaufman, Barbara Linder, Sara Mazzuto, Joan Nachmani, Jean-Baptiste Roullet, Debbe Thompson, Alissa Wheeler, Tara Wilson and Zenong Yin. We certify that all applicable institutional and governmental regulations concerning the ethical use of human volunteers were followed during this research.

\section{References}

1. The HEALTHY Study Group. HEALTHY study rationale, design and methods: moderating risk of type 2 diabetes in multi-ethnic middle school students. Int J Obes. 2009; 33(Suppl 4):S4-S20. 
2. Shavers VL, Lynch CF, Burmeister LF. Racial differences in factors that influence the willingness to participate in medical research studies. Ann Epidemiol. 2002; 12:248-256. [PubMed: 11988413]

3. Harrell JS, Bradley C, Dennis J, Frauman AC, Criswell ES. School-based research: problems of access and consent. J Pediatr Nurs. 2000; 15:14-21. [PubMed: 10714034]

4. Olds RS, Symons CW. Recommendations for obtaining cooperation to conduct school-based research. J Sch Health. 1990; 60:96-98. [PubMed: 2319755]

5. Petosa R, Goodman RM. Recruitment and retention of schools participating in school health research. J Sch Health. 1991; 61:426-429. [PubMed: 1812320]

6. Post A, Galanti MR, Gilliam H. School and family participation in a longitudinal study of tobacco use: some methodological notes. Eur J Public Health. 2003; 13:75-76. [PubMed: 12678318]

7. Croft JB, Webber LS, Parker FC, Berenson GS. Recruitment and participation of children in a longterm study of cardiovascular disease: the Bogalusa Heart Study, 1973-1982. Am J Epidemiol. 1984; 120:436-448. [PubMed: 6332531]

8. Harrington KF, Binkley D, Reynolds KD, Duvall RC, Copeland JR, Franklin F, et al. Recruitment issues in school-based research: lessons learned from the High 5 Alabama Project. J Sch Health. 1997; 67:415-421. [PubMed: 9503347]

9. Sexton K, Adgate JL, Church TR, Greaves IA, Ramachandran G, Fredrickson AL, et al. Recruitment, retention, and compliance results from a probability study of children's environmental health in economically disadvantaged neighborhoods. Environ Health Perspect. 2003; 111:731-736. [PubMed: 12727602]

10. Sexton K. Comparison of recruitment, retention, and compliance results for three children's exposure monitoring studies. J Expo Anal Environ Epidemiol. 2005; 15:350-356. [PubMed: 15523509]

11. Elder JP, Shuler L, Moe SG, Grieser M, Pratt C, Cameron S, et al. Recruiting a diverse group of middle school girls into the trial of activity for adolescent girls. J Sch Health. 2008; 78:523-531. [PubMed: 18808471]

12. Belzer EG Jr, McIntyre L, Simpson C, Officer S, Stadey N. A method to increase informed consent in school health research. J Sch Health. 1993; 63:316-317. [PubMed: 8246465]

13. Frye FH, Baxter SD, Thompson WO, Guinn CH. Influence of school, class, ethnicity, and gender on agreement of fourth graders to participate in a nutrition study. J Sch Health. 2002; 72:115-120. [PubMed: 11962227]

14. Frye FH, Baxter SD, Litaker MS, Thompson WO, Guinn CH, Baglio ML, et al. Differences in fourth-graders' participation rates across four school-based nutrition studies. J Child Nutr Manag. 2003; 27 http://docs.schoolnutrition.org/newsroom/jenm/03fall/frye/.

15. Raynor HA, Osterholt KM, Hart CN, Jelalian E, Vivier P, Wing RR. Evaluation of active and passive recruitment methods used in randomized controlled trials targeting pediatric obesity. Int $\mathbf{J}$ Pediatr Obes. 2008; 11:1-9. [PubMed: 19085199]

16. Fitzgibbon ML, Prewitt TE, Blackman LR, Simon P, Luke A, Keys LC, et al. Quantitative assessment of recruitment efforts for prevention trials in two diverse black populations. Prev Med. 1998; 27:838-845. [PubMed: 9922066]

17. Liese AD, Liu L, Davis C, Standiford D, Waitzfelder B, Dabelea D, et al. Participation in pediatric epidemiologic research: the SEARCH for Diabetes in Youth Study experience. Contemp Clin Trials. 2008; 29:829-836. [PubMed: 18573350]

18. Pound B, Riddell M, Byrnes G, Kelly H. Perception of social value predicts participation in school-based research. Aust N Z J Public Health. 2000; 24:543-545. [PubMed: 11109695]

19. Good M, Schuler L. Subject retention in a controlled clinical trial. J Adv Nurs. 1997; 26:351-355. [PubMed: 9292370]

20. Jones FC, Broome ME. Focus groups with African American adolescents: enhancing recruitment and retention in intervention studies. J Pediatr Nurs. 2001; 16:88-96. [PubMed: 11326396]

21. STOPP-T2D Prevention Study Group. Presence of diabetes risk factors in a large US eighth-grade cohort. Diabetes Care. 2006; 29:212-217. [PubMed: 16443862] 


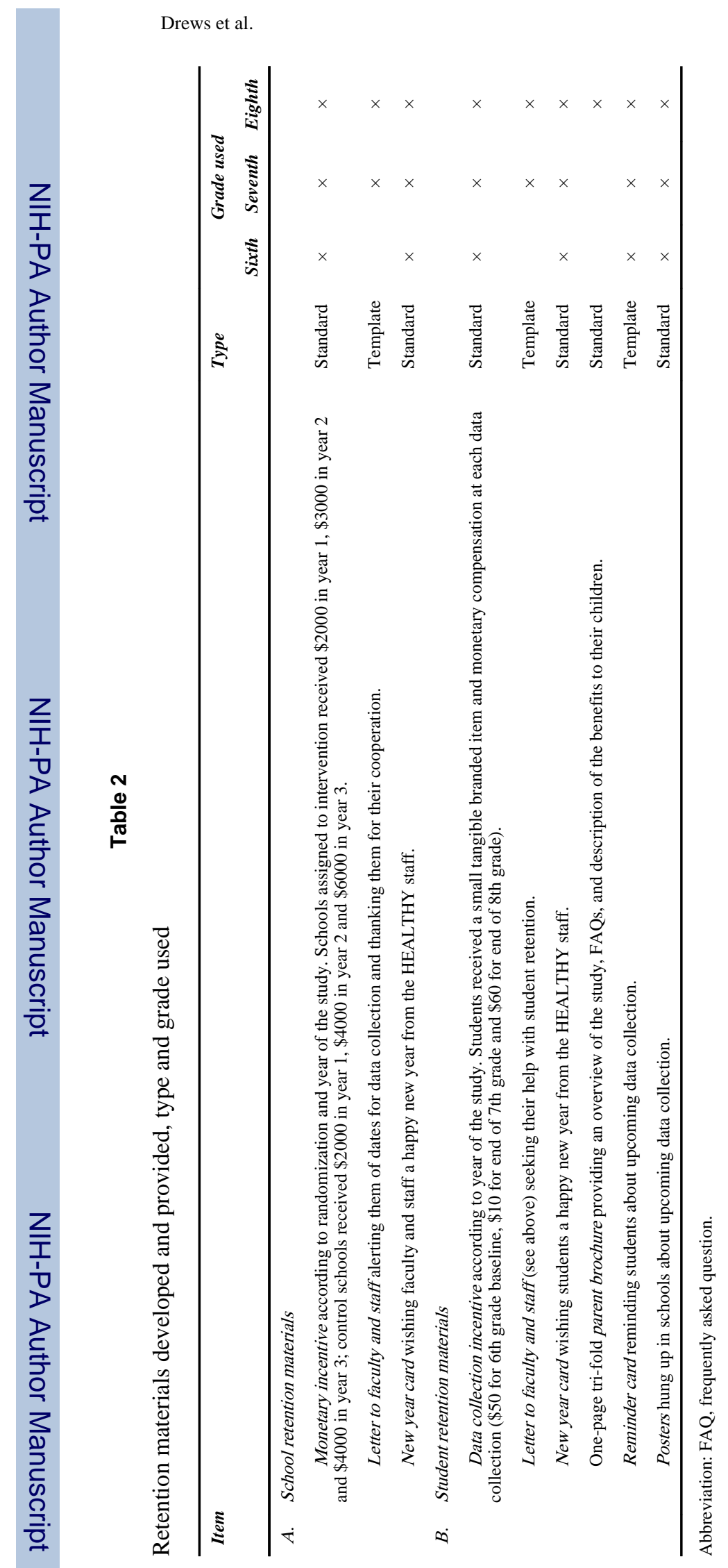

Page 12 